\title{
Semi-active vibration isolation system with variable stiffness and damping control
}

$\operatorname{AUTHOR}(\mathrm{S})$ :

LIU, Yanqing; MATSUHISA, Hiroshi; UTSUNO, Hideo

\section{CITATION:}

LIU, Yanqing ...[et al]. Semi-active vibration isolation system with variable stiffness and damping control. Journal of Sound and Vibration 2008, 313(1-2): 16-28

\section{ISSUE DATE:}

2008-06

URL:

http://hdl.handle.net/2433/89122

\section{RIGHT:}

Copyright (C) 2008 Elsevier; This is not the published version. Please cite only the published version.; この論文は出版社版でありません。引用の 際には出版社版をご確認ご利用ください。 


\title{
Semi-active vibration isolation system with variable stiffness and damping control
}

\author{
Yanqing LIU*, Hiroshi MATSUHISA, Hideo UTSUNO \\ *Department of Mechanical Engineering and Science, Kyoto University \\ Sakyo-ku, Kyoto city 606-8501, Japan, JSPS Research Fellow
}

\begin{abstract}
Semi-active systems with variable stiffness and damping have demonstrated excellent performance. However, conventional devices for controlling variable stiffness are complicated and difficult to implement in most applications. To address this issue, a new configuration using two controllable dampers and two constant springs is proposed. This paper presents theoretical and experimental analyses of the proposed system. A Voigt element and a spring in series are used to control the system stiffness. The Voigt element is comprised of a controllable damper and a constant spring. The equivalent stiffness of the whole system is changed by controlling the damper in the Voigt element, and the second damper which is parallel with the other elements provides variable damping for the system. The proposed system is experimentally implemented using two magnetorheological fluid dampers for the controllable dampers. Eight different control schemes involving soft suspension, stiff suspensions with low and high damping, damping on-off (soft and stiff), stiffness on-off (low and high), and damping and stiffness on-off control are explored. The time and frequency responses of the system to sinusoidal, impulse and random excitations show that variable stiffness and damping control can be realized by the proposed system. The system with damping and stiffness on-off control provides excellent vibration isolation for a broad range of excitations.
\end{abstract}

Key Words: Semi-active control, Vibration isolation, Variable damping, Variable stiffness, MR damper.

\section{Introduction}

In recent years, vibration isolation systems have been studied broadly and in great depth. The vibration control systems can be categorized as: passive, active and semi-active. Semi-active control systems fill the gap between passive and active control system and they represent a compromise between performance improvement and simplicity of implementation. They only expend a small amount of energy to change system parameters, such as damping and stiffness. The basic idea of variable damping systems have been proposed by many researchers to provide effective vibration control [1-4]. However, there is still room for further improvement because variable spring stiffness systems have not been thoroughly investigated in terms of their practical implementation, despite the fact that vibration systems with variable stiffness control were proposed by a few researchers $[5,6]$.

Kobori proposed a variable stiffness system to suppress buildings' response to earthquakes [6]. The aim of Kobori's work was to achieve a non-stationary and non-resonant state during earthquakes. Youn and Hac used an air spring in a suspension system to vary the stiffness among three discrete values [5]. The stiffness was changed only when the required control force could not be generated by variable damping alone. A vehicle system with variable stiffness demonstrated a good performance compared to a semi-active system

* Corresponding author, Tel.: 81-75-753-5855, Fax.: 81-75-753-5225

E-mail: yqliu@eng.mbox.media.kyoto-u.ac.jp 
with variable damping and fixed stiffness. However, conventional implementation of variable stiffness device is complicated. On the other hand, the variable damping can be easily produced by a controllable damper, such as a fluid damper with variable orifices or a magnetorheological (MR) damper [7, 8]. The authors of this paper have proposed a structure using two Voigt elements (each one composed of a controllable damper and a constant spring) in series to realize variable stiffness and damping [7]. In the system, the stiffness could be changed easily by damper. The proposed structure was experimentally implemented using two MR fluid dampers. The sinusoidal and random responses of one degree-of-freedom (DOF) and 2-DOF systems showed that the proposed damping and stiffness on-off control system using MR fluid dampers exhibited good vibration isolation performance [9, 10]. However, because two controllable dampers were installed in series in the previous system, the damping and stiffness could not be changed independently.

In this paper, a new variable stiffness and variable damping system in which the stiffness and damping can be independently and easily controlled is proposed. The responses of the proposed systems to the sinusoidal and random excitations are studied in numerical simulations and experiments.

\section{Variable stiffness and damping system}

\subsection{Mechanical structure}

A new model of one-degree-of-freedom (1-DOF) vibration isolation system with two controllable dampers (damper 1 and damper 2 corresponding damping coefficients of $c_{1}$ and $c_{2}$ ) and two springs (spring 1 and spring 2 corresponding stiffnesses of $k_{1}$ and $k_{2}$ ) shown in Fig. 1 (a) is proposed. Damper 2 and spring 2 comprise a Voigt element. The Voigt element and spring 1 are in series. The stiffness values of the two springs are constant, however, the effective stiffness of the net system can be varied by the controllable damper 2. If the damping coefficient of damper 2 is small enough, the total system stiffness approaches the series stiffnesses of spring 1 and 2. However, if the damping coefficient of damper 2 is large enough, the total stiffness approaches the stiffness of spring 1 . The damper 1 provides variable damping for the system.

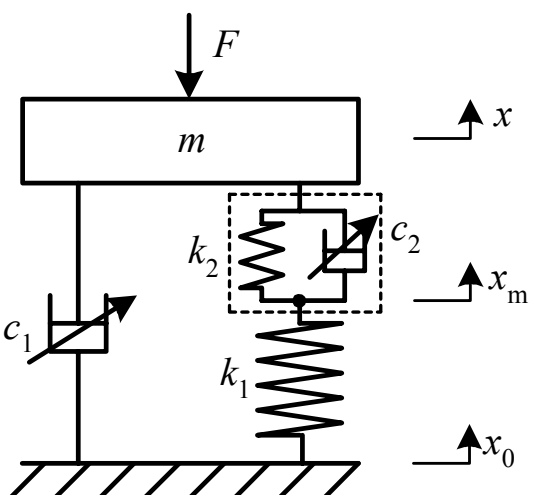

(a) Original model

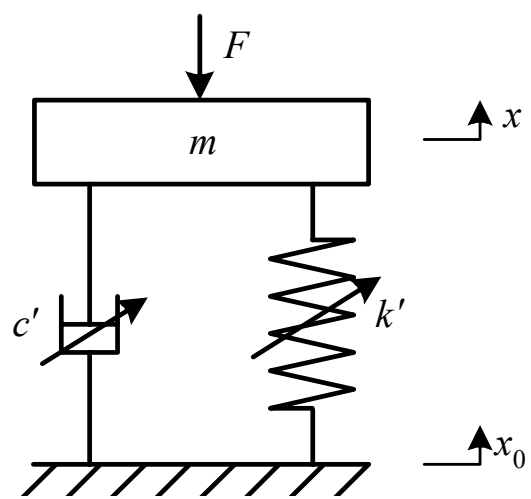

(b) Equivalent model

Fig. 1 Mechanical configuration of variable stiffness and damping.

\subsection{Equations of motion}

In Fig. 1 (a), $F$ is an excitation force, $x_{0}, x$, and $x_{\mathrm{m}}$ are displacements of base, mass $m$ and the point between the Voigt element and spring 1, respectively. In the case of a vehicle suspension, $x_{0}$ corresponds to the road bumpiness and $F$ is produced by engine vibration. Figure 1 (b) shows the equivalent model of the system. Here $k^{\prime}$ and $c^{\prime}$ are equivalent stiffness and damping coefficient, respectively. The equations of motion for the system shown in Fig. 1 (a) are

$$
\begin{gathered}
m \ddot{x}=-k_{2}\left(x-x_{m}\right)-c_{2}\left(\dot{x}-\dot{x}_{m}\right)-c_{1}\left(\dot{x}-\dot{x}_{0}\right)-F, \\
k_{1}\left(x_{m}-x_{0}\right)=k_{2}\left(x-x_{m}\right)+c_{2}\left(\dot{x}-\dot{x}_{m}\right),
\end{gathered}
$$

where (") and (') mean $d^{2} / d t^{2}$ and $d / d t$. When only the base excitation is considered $(F=0)$, the transfer function of the system is 


$$
\frac{X}{X_{0}}=\frac{k_{1}-\frac{k_{1}^{2}\left(k_{1}+k_{2}\right)}{\left(k_{1}+k_{2}\right)^{2}+c_{2}^{2} \omega^{2}}+i\left[c_{1}+\frac{k_{1}^{2} c_{2}}{\left(k_{1}+k_{2}\right)^{2}+c_{2}^{2} \omega^{2}}\right] \omega}{-m \omega^{2}+k_{1}-\frac{k_{1}^{2}\left(k_{1}+k_{2}\right)}{\left(k_{1}+k_{2}\right)^{2}+c_{2}^{2} \omega^{2}}+i\left[c_{1}+\frac{k_{1}^{2} c_{2}}{\left(k_{1}+k_{2}\right)^{2}+c_{2}^{2} \omega^{2}}\right] \omega},
$$

where $x_{0}=X_{0} e^{i \omega t}, x=X e^{i \omega t}, t$ is the time and $\omega$ is the excitation frequency. When only the force excitation is considered $\left(x_{0}=0\right)$, the compliance is given by

$$
\frac{X}{F_{0}}=\frac{-1}{-m \omega^{2}+k_{1}-\frac{k_{1}{ }^{2}\left(k_{1}+k_{2}\right)}{\left(k_{1}+k_{2}\right)^{2}+c_{2}{ }^{2} \omega^{2}}+i\left[c_{1}+\frac{k_{1}{ }^{2} c_{2}}{\left(k_{1}+k_{2}\right)^{2}+c_{2}{ }^{2} \omega^{2}}\right] \omega},
$$

where $F=F_{0} e^{i \omega t}$. The corresponding transfer functions of the equivalent model shown in Fig. 1 (b) are

$$
\begin{aligned}
& \frac{X}{X_{0}}=\frac{k^{\prime}+i c^{\prime} \omega}{-m \omega^{2}+k^{\prime}+i c^{\prime} \omega}, \\
& \frac{X}{F_{0}}=\frac{-1}{-m \omega^{2}+k^{\prime}+i c^{\prime} \omega} .
\end{aligned}
$$

Comparing Eqs. (3) and (4) with Eqs. (5) and (6), the equivalent stiffness and damping coefficient are

$$
\begin{gathered}
k^{\prime}=k_{1}-\frac{k_{1}^{2}\left(k_{1}+k_{2}\right)}{\left(k_{1}+k_{2}\right)^{2}+c_{2}^{2} \omega^{2}}=k_{1}\left[1-\frac{1+\alpha}{(1+\alpha)^{2}+4 \alpha \varsigma_{2}^{2} r^{2}}\right], \\
c^{\prime}=c_{1}+\frac{k_{1}^{2} c_{2}}{\left(k_{1}+k_{2}\right)^{2}+c_{2}^{2} \omega^{2}}=c_{1}\left[1+\frac{1}{(1+\alpha)^{2}+4 \alpha \varsigma_{2}^{2} r^{2}} \times \frac{\sqrt{\alpha} \varsigma_{2}}{\varsigma_{1}}\right],
\end{gathered}
$$

where $\alpha=k_{2} / k_{1}, r=\omega / \omega_{\mathrm{n} 1}, \omega_{\mathrm{n} 1}=\sqrt{k_{1} / m}, \varsigma_{1}=c_{1} / 2 \sqrt{m k_{1}}$, and $\varsigma_{2}=c_{2} / 2 \sqrt{m k_{2}}$. Equations (7) and (8) show that $k^{\prime}$ is independent of $c_{1}$, and $k^{\prime}$ and $c^{\prime}$ are influenced by $c_{2}$. If $c_{2}=\infty$, then $k^{\prime}=k_{1}$ and $c^{\prime}=c_{1}$. If $c_{2}=0$, then $k^{\prime}=k_{1} k_{2} /\left(k_{1}+k_{2}\right)$ and $c^{\prime}=c_{1}$. By letting $m=1 \mathrm{~kg}, k_{1}=4 \pi^{2} \mathrm{~N} / \mathrm{m}, k_{2} / k_{1}=1 / 3$, and $\varsigma_{1}=0.01$ (these values give the natural frequencies of $0.5 \mathrm{~Hz}$ for $c_{2}=0$ and $1 \mathrm{~Hz}$ for $c_{2}=\infty$.), Fig. 2 shows frequency responses of the system. The resonant frequency can be varied by $\varsigma_{2}$, and when is $\varsigma_{2}$ is small $\left(\varsigma_{2}<1.0\right)$, the compliance in the low frequency region has large value.

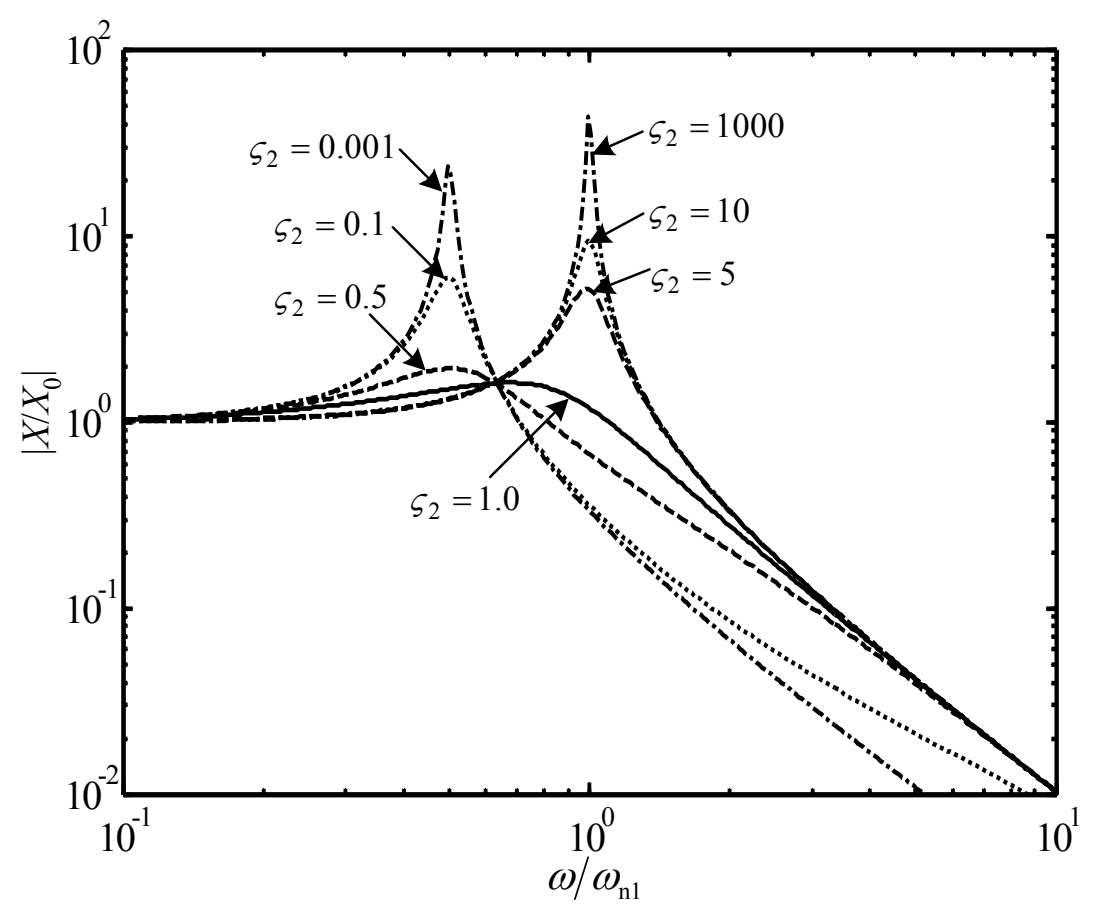

(a) Base excitation 


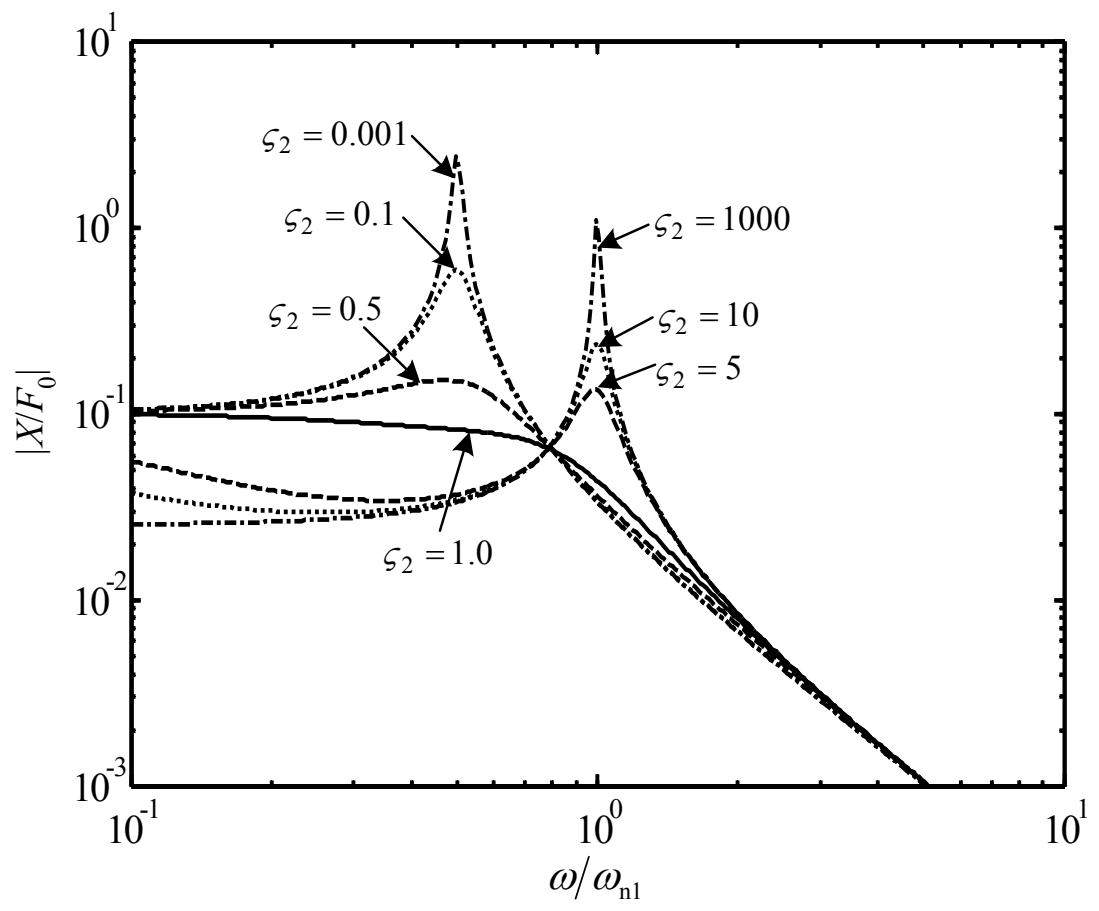

(b) Force excitation

Fig. 2 Frequency responses of the vibration system varied by damper $2\left(\varsigma_{1}=0.01\right)$.

\subsection{Equivalent stiffness and damping}

Figures 3 and 4 show the values of $k^{\prime}$ and $c^{\prime}$ as functions of $\varsigma_{2}$ and $k_{2} / k_{1}$ for $\varsigma_{1}=0.1,0.3$ and $0.5\left(k_{1}=4 \pi^{2}\right.$ $\mathrm{N} / \mathrm{m}$ and $m=1 \mathrm{~kg}$ ). When $k_{2} / k_{1}=1 / 3,1.0$ and 3.0, and $\varsigma_{2}=0.1,1$ and 10, the corresponding values of $k^{\prime}$ and $c^{\prime}$ are also shown by thick solid lines in the figures. The exciting frequencies are $\omega=0.1 \omega_{\mathrm{n} 1}, \omega_{\mathrm{n} 1}$, and $10 \omega_{\mathrm{n} 1}$.

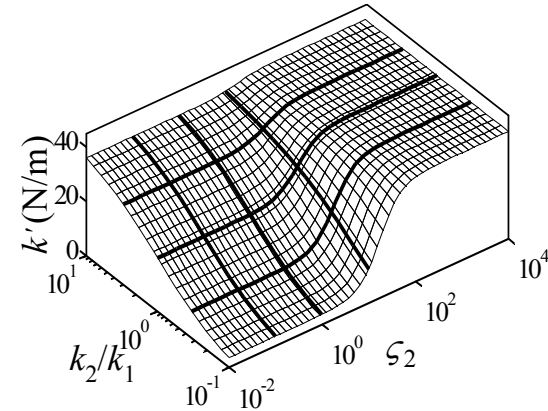

(a) $\omega=0.1 \omega_{\mathrm{n} 1}$

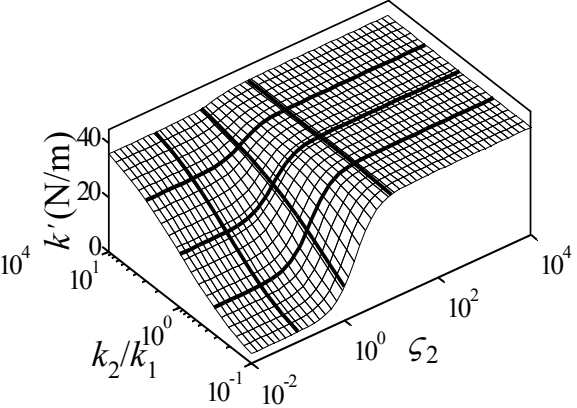

(b) $\omega=\omega_{\mathrm{n} 1}$

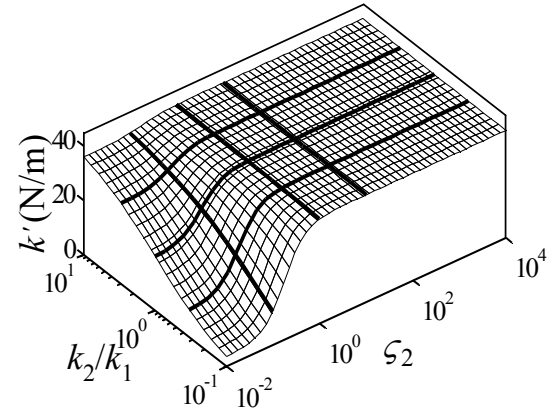

(c) $\omega=10 \omega_{\mathrm{n} 1}$

Fig. 3 Equivalent stiffness of the system.
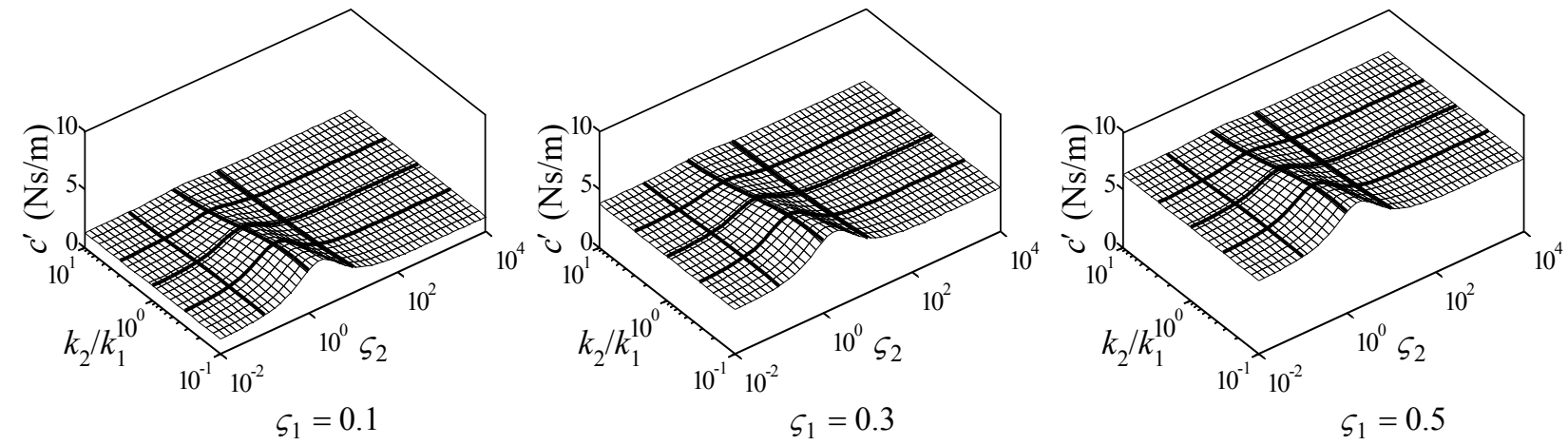

(a) $\omega=\omega_{\mathrm{n} 1}$ 

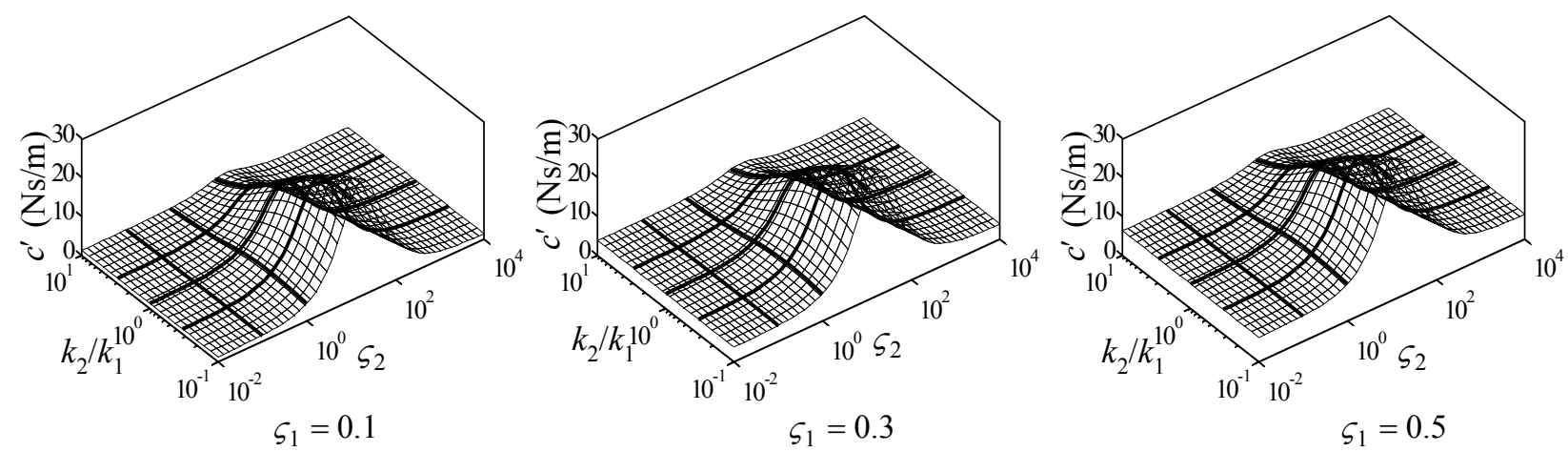

(b) $\omega=0.1 \omega_{\mathrm{n} 1}$
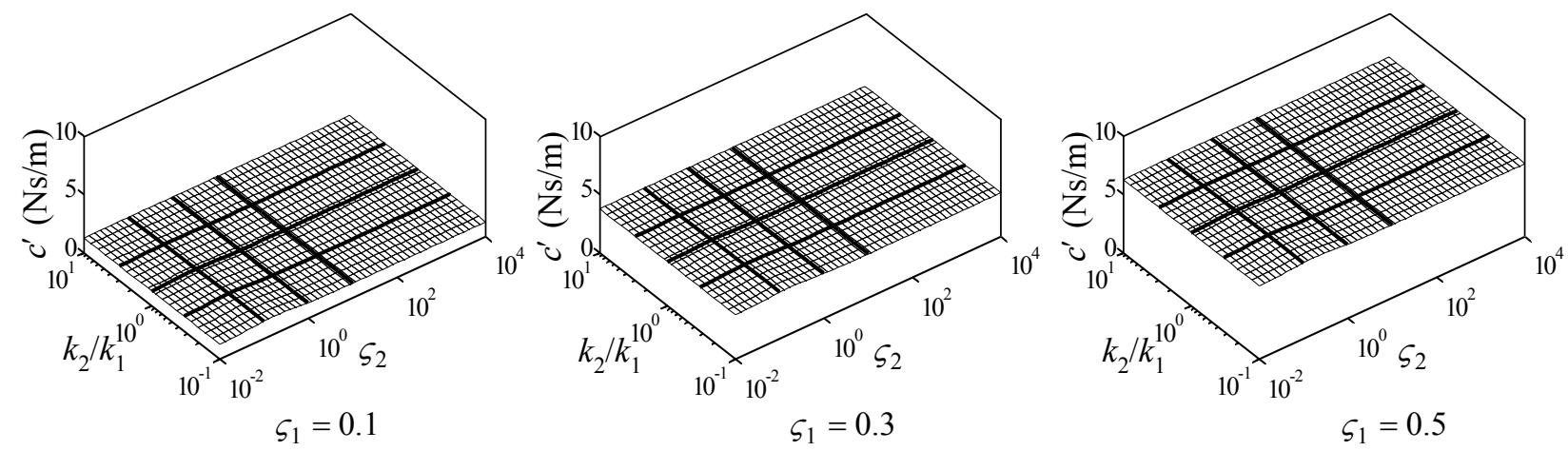

(c) $\omega=10 \omega_{\mathrm{n}}$

Fig. 4 Equivalent damping coefficient of the system.

Figure 3 shows that when the stiffness ratio $k_{2} / k_{1}$ is small $\left(k_{2} / k_{1}=0.1\right), k^{\prime}$ can be varied significantly by changing $\varsigma_{2}$. However, when it is large $\left(k_{2} / k_{1}=10\right), k^{\prime}$ can be changed by a small amount by varying $\varsigma_{2}$. For practical applications, the stiffness ratio $k_{2} / k_{1}$ should be small in order to achieve a large variation of stiffness by changing damper 2 . In the following numerical calculations considering the experimental apparatus, $k_{2} / k_{1}=1 / 3$ is used. The equivalent stiffness can be changed 4.0 times.

Based on Fig. 4, when $\omega=10 \omega_{\mathrm{n} 1}, c^{\prime}$ is almost independent on $\varsigma_{2}$, and when $\omega=\omega_{\mathrm{n} 1}, c^{\prime}$ is slightly affected by $\varsigma_{2}$. When $\omega=0.1 \omega_{\mathrm{n} 1}, c^{\prime}$ has a high peak at $\varsigma_{2}=(1+\alpha) / 2 \sqrt{\alpha} r$. However, since the isolation is designed for the high frequency region, the low frequency region can be neglected. Therefore, it can be concluded that $c^{\prime}$ can be controlled by $\varsigma_{1}$ dependently when the value of $\varsigma_{2}$ is changed from a very small value to a very large very value

\subsection{On-off control algorithms}

The on-off control algorithm of damper 1 uses the sign of the absolute velocity and the relative velocity [1]. The force $f_{\mathrm{d} 1}$ generated by damper 1 is

$$
f_{\mathrm{d} 1}=\left\{\begin{array}{lll}
-c_{1 \text { on }}\left(\dot{x}-\dot{x}_{0}\right) & \text { if } & \dot{x}\left(\dot{x}-\dot{x}_{0}\right) \geq 0 \\
-c_{1 \text { off }}\left(\dot{x}-\dot{x}_{0}\right) & \text { if } & \dot{x}\left(\dot{x}-\dot{x}_{0}\right)<0
\end{array},\right.
$$

where the damping coefficient $c_{1}$ is equal to $c_{1 \text { on }}$ in the on-state and $c_{1 \text { off }}$ in the off-state. The control algorithm for damper 2 uses the sign of $\dot{x}\left(x-x_{0}\right)$ [7]. The force $f_{\mathrm{d} 2}$ exerted by damper 2 is

$$
f_{\mathrm{d} 2}=\left\{\begin{array}{lll}
-c_{2 \mathrm{on}}\left(\dot{x}-\dot{x}_{m}\right) & \text { if } & \dot{x}\left(x-x_{0}\right) \geq 0 \\
-c_{2 \mathrm{off}}\left(\dot{x}-\dot{x}_{m}\right) & \text { if } & \dot{x}\left(x-x_{0}\right)<0
\end{array},\right.
$$

Eight types of control schemes shown in Table 1 are compared. In the Type 1 system, damper 1 and damper 2 are always in the off-sates and the total stiffness is the small ("Soft suspension"). In the Type 2 system, damper 1 is in the off-state and damper 2 is in the on-state ("Low damping"). In the Type 3 system, damper 1 and 2 are both in the on-state ("High damping"). Because damper 2 is always in the on-state and the total 
stiffness is large in the low and high damping systems, they are typically called "stiff suspension". In the Type 4 system, damper 1 is on-off controlled as given by Eq. (9) and damper 2 is in the off-state ("D on-off (soft)"). In the Type 5 system, damper 1 is on-off controlled as given by Eq. (9) and damper 2 is in the onstate ("D on-off (stiff)"). In the Type 6 system, damper 1 is in the off-state and damper 2 is on-off controlled as given by Eq. (10) ("S on-off (low)"). In the Type 7 system, damper 1 is in the on-state and damper 2 is onoff controlled as given by Eq. (10) ("S on-off (high)"). In the Type 8 system, damper 1 and 2 are on-off controlled ("D+S on-off"). Types 1, 2, and 3 are passive systems, while Types 4, 5, 6, 7, and 8 are semiactive control systems.

Table 1 Control systems

\begin{tabular}{c|c|c|c}
\hline \hline & Name & Damper 1 & Damper 2 \\
\hline Type 1 & Soft system & off & off \\
\hline Type 2 & Low damping & off & on \\
\hline Type 3 & High damping & on & on \\
\hline Type 4 & D on-off (soft) & on-off & off \\
\hline Type 5 & D on-off (stiff) & on-off & on \\
\hline Type 6 & S on-off (low) & off & on-off \\
\hline Type 7 & S on-off (high) & on & on-off \\
\hline Type 8 & D+S on-off & on-off & on-off \\
\hline
\end{tabular}

\section{Frequency and time responses}

\subsection{Frequency responses to a sinusoidal excitation}

Based on the limitations of experimental apparatus used in this work, the following values were used in the numerical calculation: $c_{1 \text { off }}=0.4 \pi \mathrm{Ns} / \mathrm{m}\left(\varsigma_{1 \text { off }}=0.1\right), c_{1 \text { on }}=2.0 \pi \mathrm{Ns} / \mathrm{m}\left(\varsigma_{1 \text { on }}=0.5\right), c_{2 \text { off }}=0.23 \pi \mathrm{Ns} / \mathrm{m}\left(\varsigma_{2 \text { off }}=0.1\right)$, and $c_{2 \mathrm{on}}=23.1 \pi \mathrm{Ns} / \mathrm{m}\left(\varsigma_{2 \mathrm{on}}=10\right)$. When $X_{0}=0.01 \mathrm{~m}$, the values $\left|X / X_{0}\right|$ of the system with eight control schemes are shown in Fig. 5 (a). When $F_{0}=0.04 \pi^{2} \mathrm{~N}$, the values $\left|X / F_{0}\right|$ of the system are shown in Fig. 5 (b). Because the base does not move in the force excitation case $\left(\dot{x}_{0}=0\right)$, the term $\dot{x}\left(\dot{x}-\dot{x}_{0}\right)$ is always positive or zero, and damper 1 is always in the on-state. Therefore, the "D on-off (stiff)" control system behaves similarly to the high damping system, and the " $\mathrm{D}+\mathrm{S}$ on-off" control system behaves similarly to the "S on-off (high)" control system in Fig. 5 (b).

Figure 5 (a) shows that "D+S on-off" and "D on-off (soft)" control systems have good performances, because their responses do not exhibit resonant peaks at $0.5 \omega_{\mathrm{n} 1}$ and $\omega_{\mathrm{n} 1}$, and the $\left|X / X_{0}\right|$ values are small in the high frequency region. Based on Fig. 5 (b), "D+S on-off", "S on-off (high)", "D on-off (stiff)" and high control systems have good performances in the resonant and low frequency regions. Therefore, the " $\mathrm{D}+\mathrm{S}$ onoff" control system may have good performances in the both cases of base and force excitations. 


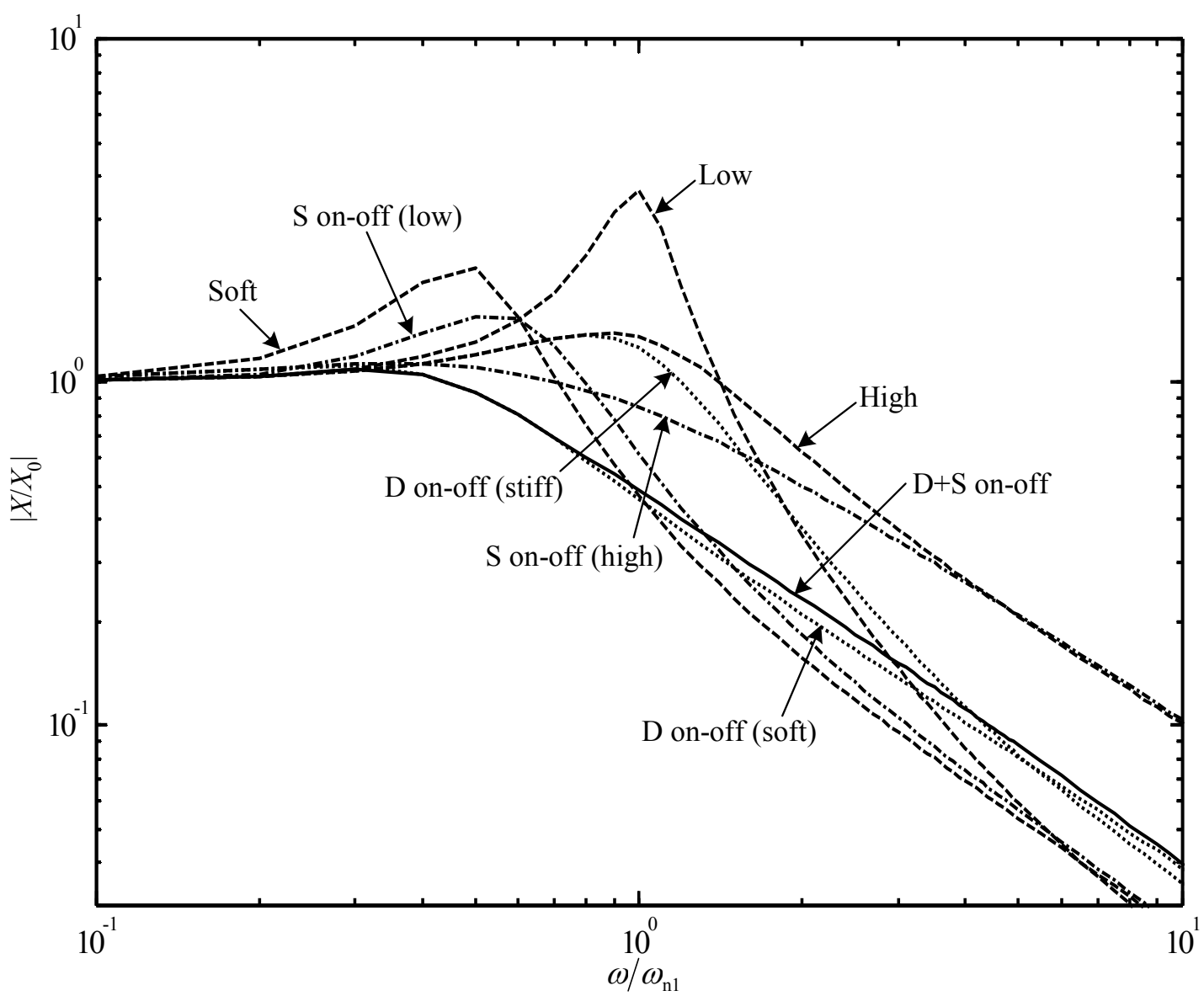

(a) Base excitation

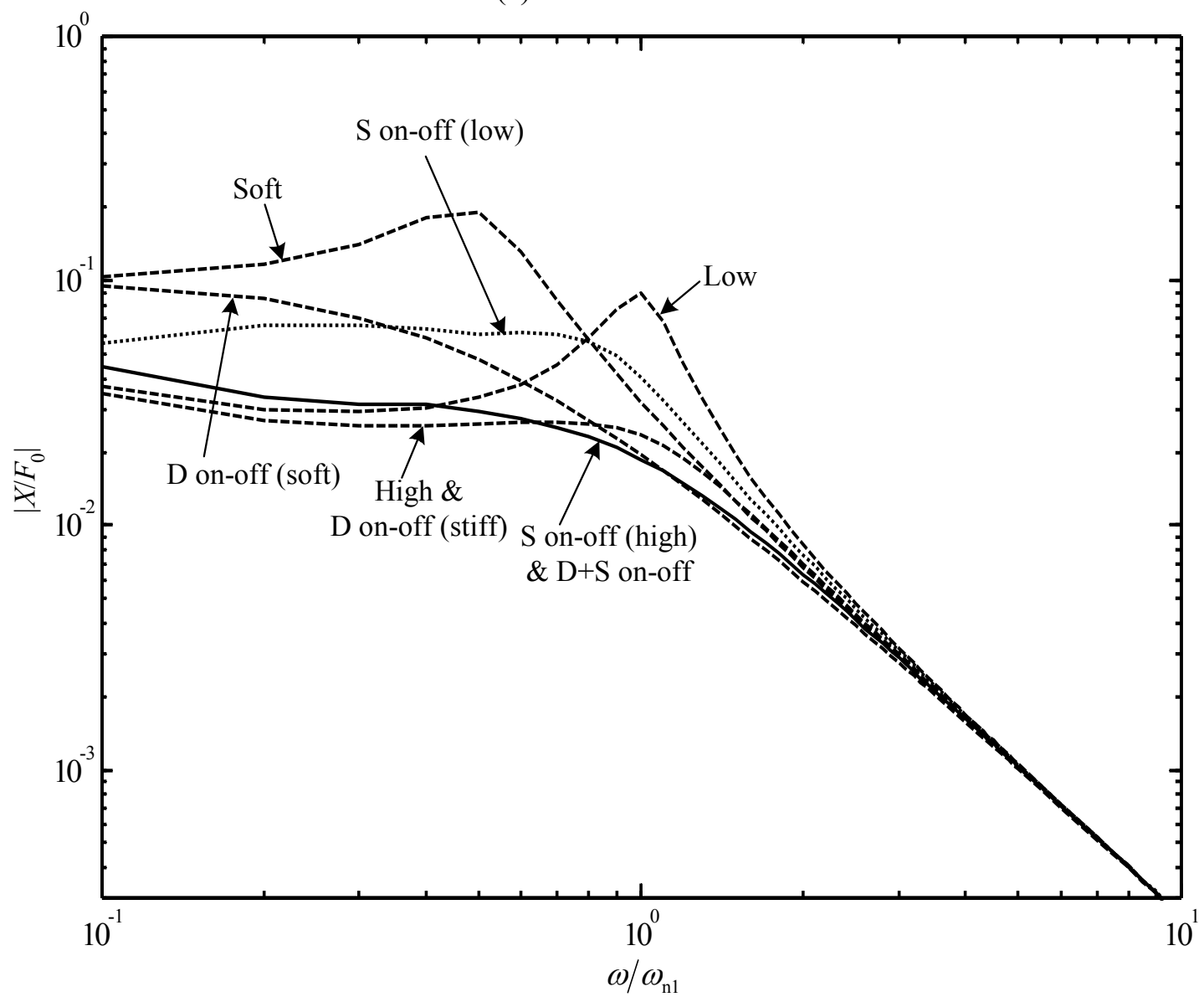

(b) Force excitation

Fig. 5 Frequency responses of the system to a sinusoidal excitation. 


\subsection{Time responses to a random excitation}

The response to a random base excitation simulates a vehicle traveling on an actual road. It is commonly accepted that the spectrum of a geometrical road profile, $P(n)$, can be approximated as

$$
P(n)=\left\{\begin{array}{l}
P\left(n_{0}\right)\left(\frac{n}{n_{0}}\right)^{-w_{1}}, \quad \text { if } \quad n \leq n_{0}, \\
P\left(n_{0}\right)\left(\frac{n}{n_{0}}\right)^{-w_{2}}, \quad \text { if } \quad n>n_{0}
\end{array}\right.
$$

where $w_{1}=2.0$ and $w_{2}=1.5$, and $n_{0}=1 / 2 \pi \mathrm{c} / \mathrm{m}, n$ is a spatial frequency, and $P\left(n_{0}\right)$ is the road roughness [11]. In this study, three classes of roads are used: A) smooth, $\left.P\left(n_{0}\right)=16 \times 10^{-6} \mathrm{~m}^{3} / \mathrm{c}, \mathrm{B}\right)$ average, $P\left(n_{0}\right)=64 \times 10^{-6} \mathrm{~m}^{3} / \mathrm{c}$, and C) Rough, $P\left(n_{0}\right)=256 \times 10^{-6} \mathrm{~m}^{3} / \mathrm{c}$ [12]. Considering a vehicle traveling with speed $v_{0}$, the road irregularity is described by

$$
x_{0}(t)=\sum_{\mathrm{i}=1}^{\mathrm{N}} A_{\mathrm{i}} \sin \left(\mathrm{i} \omega_{0} t+\varphi_{\mathrm{i}}\right),
$$

where $\varphi_{\mathrm{i}}$ is a random variable with a uniform distribution in the interval $[0,2 \pi], A_{\mathrm{i}}=\sqrt{2 P(\mathrm{i} \Delta n) \Delta n}, \mathrm{i}=1,2$, $3, \ldots, N, \Delta n=2 \pi / L, L$ is the length of the road segment [13]. The value of $\omega_{0}$ is determined by

$$
\omega_{0}=\frac{2 \pi}{L} v_{0}
$$

In this analysis, $v_{0}=20 \mathrm{~m} / \mathrm{s}, N=100, L=200 \mathrm{~m}, \Delta t=0.005 \mathrm{~s}$. Figure 6 describes the time histories and power spectral densities (PSD) of three classes roads. In the calculation, the frequency region of the input signal is from $0.1 \mathrm{~Hz}$ to $10 \mathrm{~Hz}$. The time responses of the systems with B class excitation are shown in Fig. 7, and the root mean square (RMS) values are showed in Table 2.

According to Fig. 7 and Table 2, the displacement of " $\mathrm{D}+\mathrm{S}$ on-off" control system is the smallest among the eight control systems. The acceleration of " $D+S$ on-off" control system is larger than those of "Soft", "D on-off (soft)" and "S on-off (low)" control systems, however, these systems have bad $\left|X / F_{0}\right|$ performances in the low frequency as shown in Fig. 5 (b). Therefore, the " $\mathrm{D}+\mathrm{S}$ on-off" control has good performances in a random exciting case.

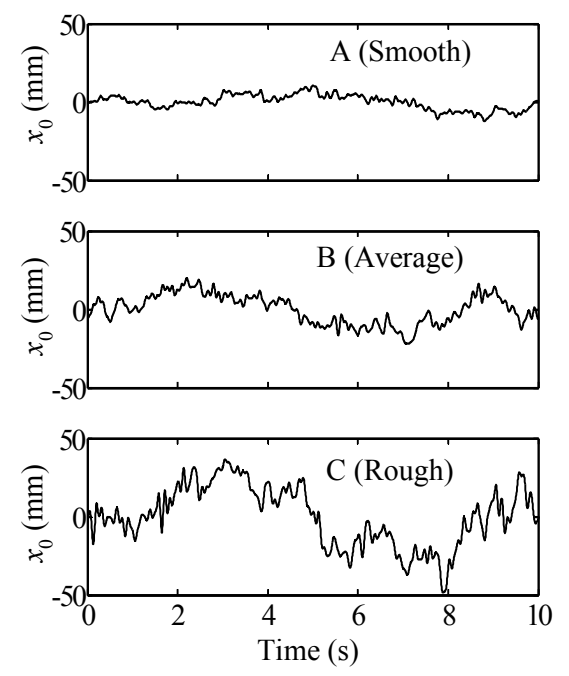

(a) Time history

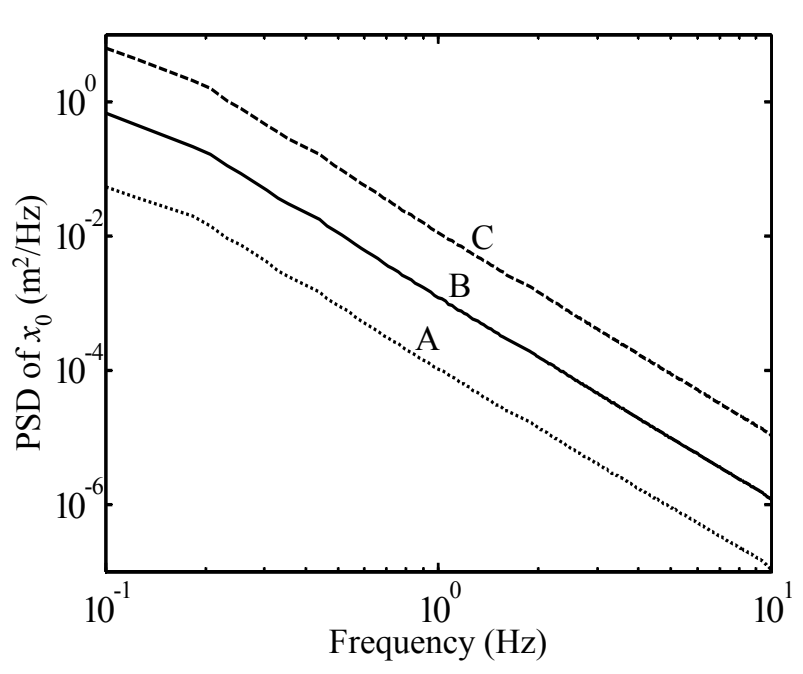

(b) PSD values

Fig. 6 Three class excitations. 

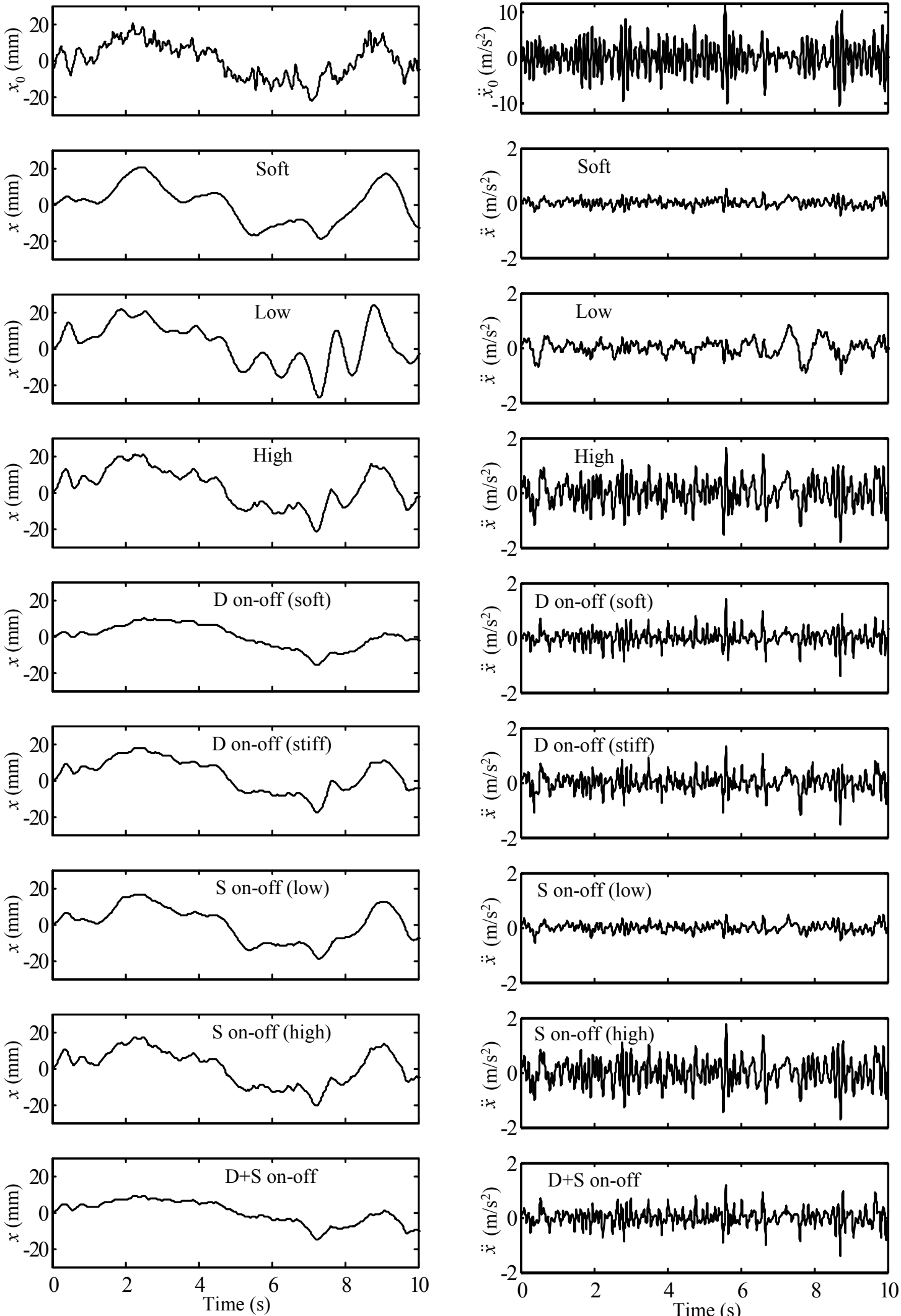

(a) Displacements

(b) Accelerations

Fig. 7 Time responses to a random base excitation. 
Table 2 RMS values of the system with a random base excitation.

\begin{tabular}{c|c|c|c|c|c|c}
\hline \hline \multirow{2}{*}{ Soft system } & \multicolumn{2}{|c|}{ A (Smooth) } & \multicolumn{2}{c|}{ B (Average) } & \multicolumn{2}{c}{ C (Rough) } \\
\cline { 2 - 7 } & $x(\mathrm{~mm})$ & $\ddot{x}\left(\mathrm{~m} / \mathrm{s}^{2}\right)$ & $x(\mathrm{~mm})$ & $\ddot{x}\left(\mathrm{~m} / \mathrm{s}^{2}\right)$ & $x(\mathrm{~mm})$ & $\ddot{x}\left(\mathrm{~m} / \mathrm{s}^{2}\right)$ \\
\hline Low damping & 5.50 & 0.14 & 11.15 & 0.29 & 22.05 & 0.57 \\
\hline High damping & 4.87 & 0.24 & 9.88 & 0.49 & 19.52 & 0.98 \\
\hline D on-off (soft) & 3.09 & 0.12 & 6.54 & 0.24 & 14.18 & 0.51 \\
\hline D on-off (stiff) & 4.18 & 0.14 & 8.42 & 0.30 & 17.61 & 0.60 \\
\hline S on-off (low) & 4.94 & 0.08 & 9.62 & 0.15 & 18.63 & 0.31 \\
\hline S on-off (high) & 4.77 & 0.24 & 9.48 & 0.47 & 19.03 & 0.94 \\
\hline D+S on-off & 2.69 & 0.12 & 6.02 & 0.26 & 13.54 & 0.53 \\
\hline
\end{tabular}

\section{Experiments}

\subsection{Experimental setup}

Figure 8 shows the experimental setup of the proposed vibration system. The mass is supported by leaf springs (spring 1 and 2); and the system base is shaken in horizontal direction using an electromagnetic vibration exciter and a signal generator. Two MR fluid dampers (RD 1097 Lord Cooperation), damper 1 and 2, are used to provide the variable damping. Damper 2 is located between the mass and midpoint; moreover, damper 1 connects the mass with the base by steel stays. Because the stays are very stiff, their deformations in these experiments are negligible. Damper 2 and spring 2 comprise a Voigt element. The Voigt element and spring 1 are in series. In these experiments, the displacements $x_{0}$ and $x$ are measured by laser displacement sensors. The velocities $\dot{x}$ and $\dot{x}_{0}$ are obtained by differentiating the displacements in the controller. The voltages to DC power supplies control the currents to MR dampers. 


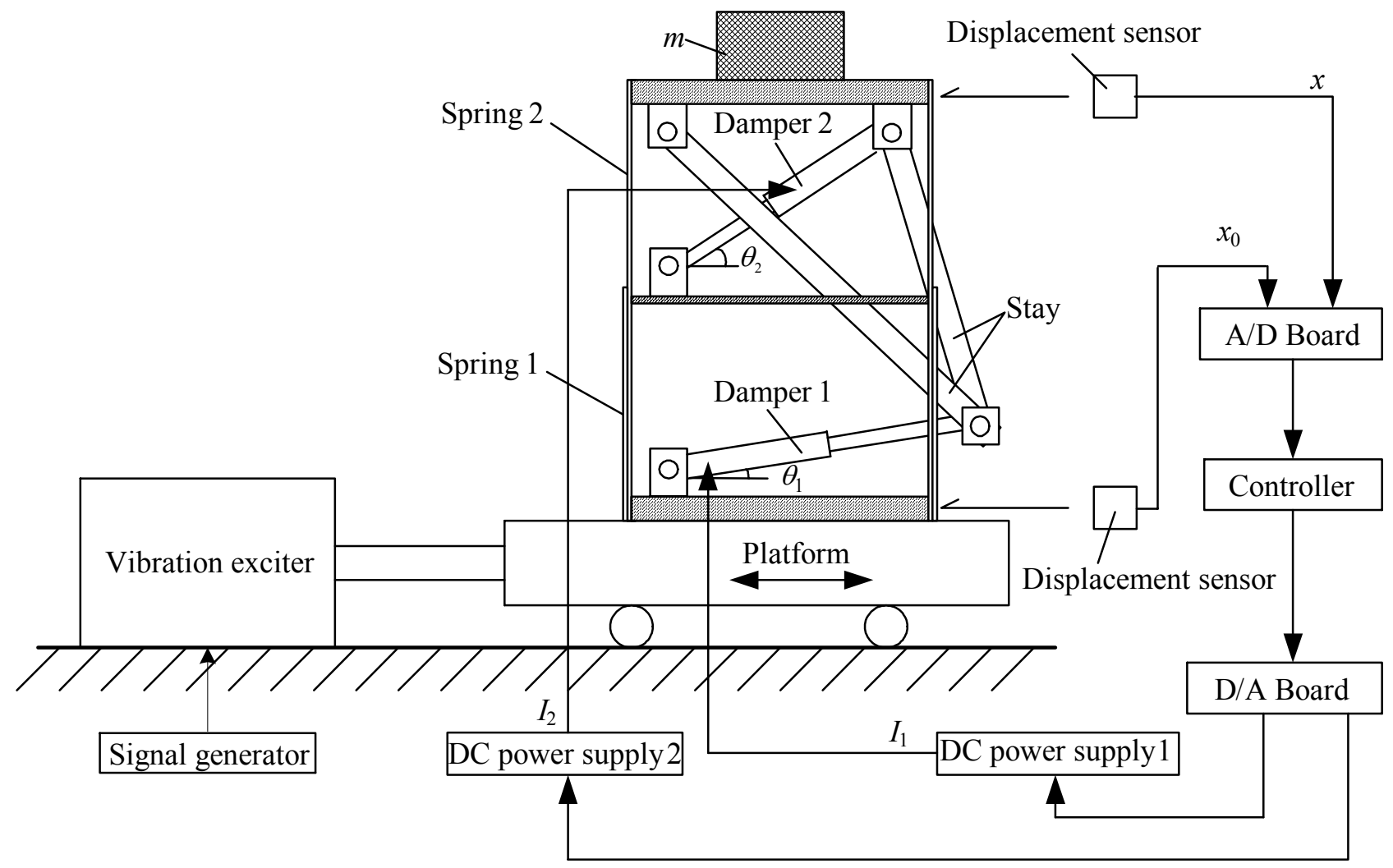

(a) Experimental system

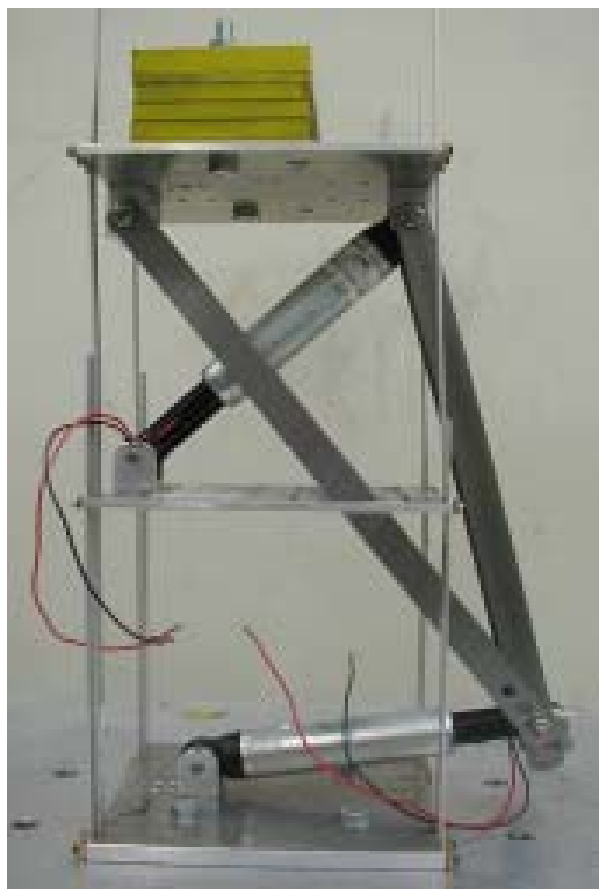

(b) Photograph of the experimental apparatus

Fig. 8 Experimental setup.

\subsection{Parameter values in experiments}

The values corresponding to the parameters of the experimental setup are listed in Table 3 . The equivalent mass of the experimental structure is included in $m$. In general, MR fluid dampers have friction forces $[8,9]$. Therefore, the equivalent damping coefficients are obtained by the system's responses in other preliminary experiments. Based 
on Eqs. (7) and (8), the values of $k^{\prime}, c^{\prime}, \varsigma^{\prime}$, and resonant frequency $f_{\mathrm{n}}$ for $\omega=\omega_{\mathrm{n} 1}$ are shown in Table 4. According to Table 4, the total stiffness $k^{\prime}$ is changed 2.8 times by varying damper 2 from the off-state to the on-state. The total damping coefficient $c^{\prime}$ is varied 3.6 times. The total damping and stiffness values are varied by damper 1 and 2 almost independently. Moreover, the natural frequency $f_{\mathrm{n}}$ is changed from $1.99 \mathrm{~Hz}$ to $3.35 \mathrm{~Hz}$ by altering the system stiffness from soft to stiff.

Table 3 Parameter values of experimental setup.

\begin{tabular}{c|c||c|c||c|c||c|c}
\hline \hline Parameters & Values & Parameters & Values (A) & Parameters & Values (Ns/m) & Parameters & Values \\
\cline { 3 - 7 } & $10.5 \mathrm{~kg}$ & $I_{\text {loff }}$ & 0 & $c_{\text {loff }}$ & $3.62 \times 10$ & $\varsigma_{\text {loff }}$ & 0.08 \\
\hline$k_{1}$ & $4.68 \times 10^{3} \mathrm{~N} / \mathrm{m}$ & $I_{\text {lon }}$ & 0.19 & $c_{\text {lon }}$ & $1.55 \times 10^{2}$ & $\varsigma_{\text {lon }}$ & 0.35 \\
\cline { 2 - 7 } & $2.51 \times 10^{3} \mathrm{~N} / \mathrm{m}$ & $I_{2 \text { off }}$ & 0 & $c_{2 \text { off }}$ & $2.01 \times 10$ & $\varsigma_{2 \text { off }}$ & 0.06 \\
\hline$k_{2}$ & $10.8^{\circ}$ & $I_{2 \text { on }}$ & 0.48 & $c_{2 \text { on }}$ & $6.00 \times 10^{3}$ & $\varsigma_{2 \text { on }}$ & 18.47 \\
\hline$\theta_{1}$ & $42.9^{\circ}$ & & & & & & \\
\hline
\end{tabular}

Table 4 Values of equivalent stiffness and damping coefficient in the experiment.

\begin{tabular}{c|c|c|c|c|c}
\hline \hline Damper 1 & Damper 2 & $k^{\prime}(\mathrm{N} / \mathrm{m})$ & $c^{\prime}(\mathrm{Ns} / \mathrm{m})$ & $\varsigma^{\prime}$ & $f_{\mathrm{n}}(\mathrm{Hz})$ \\
\hline off & off & $1.64 \times 10^{3}$ & $4.47 \times 10$ & 0.170 & 1.99 \\
\hline off & on & $4.67 \times 10^{3}$ & $4.44 \times 10$ & 0.100 & 3.35 \\
\hline on & off & $1.64 \times 10^{3}$ & $1.64 \times 10^{2}$ & 0.622 & 1.99 \\
\hline on & on & $4.67 \times 10^{3}$ & $1.63 \times 10^{2}$ & 0.368 & 3.35 \\
\hline
\end{tabular}

\subsection{Experimental results}

\subsubsection{Frequency responses to a sinusoidal base excitation}

The steady-state responses of $\left|X / X_{0}\right|$ are shown in Fig. 9, where the amplitude of a sinusoidal displacement $x_{0}$ is 5 $\mathrm{mm}$ and the exciting frequency is changed from $1 \mathrm{~Hz}$ to $10 \mathrm{~Hz}$. Because of limitations of the electromagnetic vibration exciter, the experimental results are limited to the frequency range from $1 \mathrm{~Hz}$ to $10 \mathrm{~Hz}$. Based on Fig. 9 , the calculation results are in good agreement with those of the experiment. 


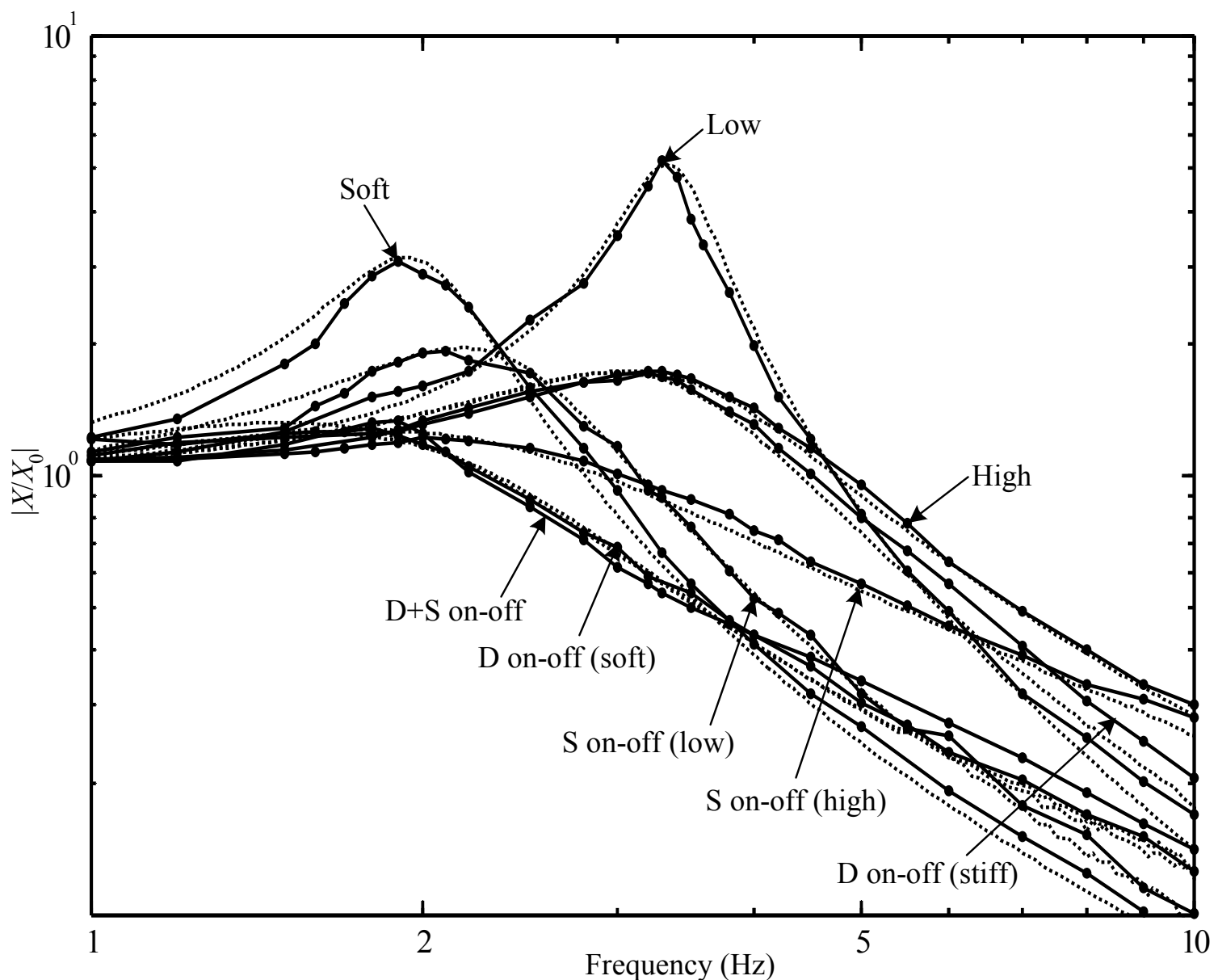

Fig. 9 Frequency responses to a sinusoidal base excitation (experiment: $\longrightarrow$ - , calculation: ---------- ).

\subsubsection{Responses to a random base excitation}

Figure 10 shows the time responses to a random base excitation. The RMS values of the responses are shown in the brackets. The time history of the input displacement $x_{0}$ is also shown in this figure. The response of " $\mathrm{D}+\mathrm{S}$ onoff" control system is the smallest among those of the eight control systems. 

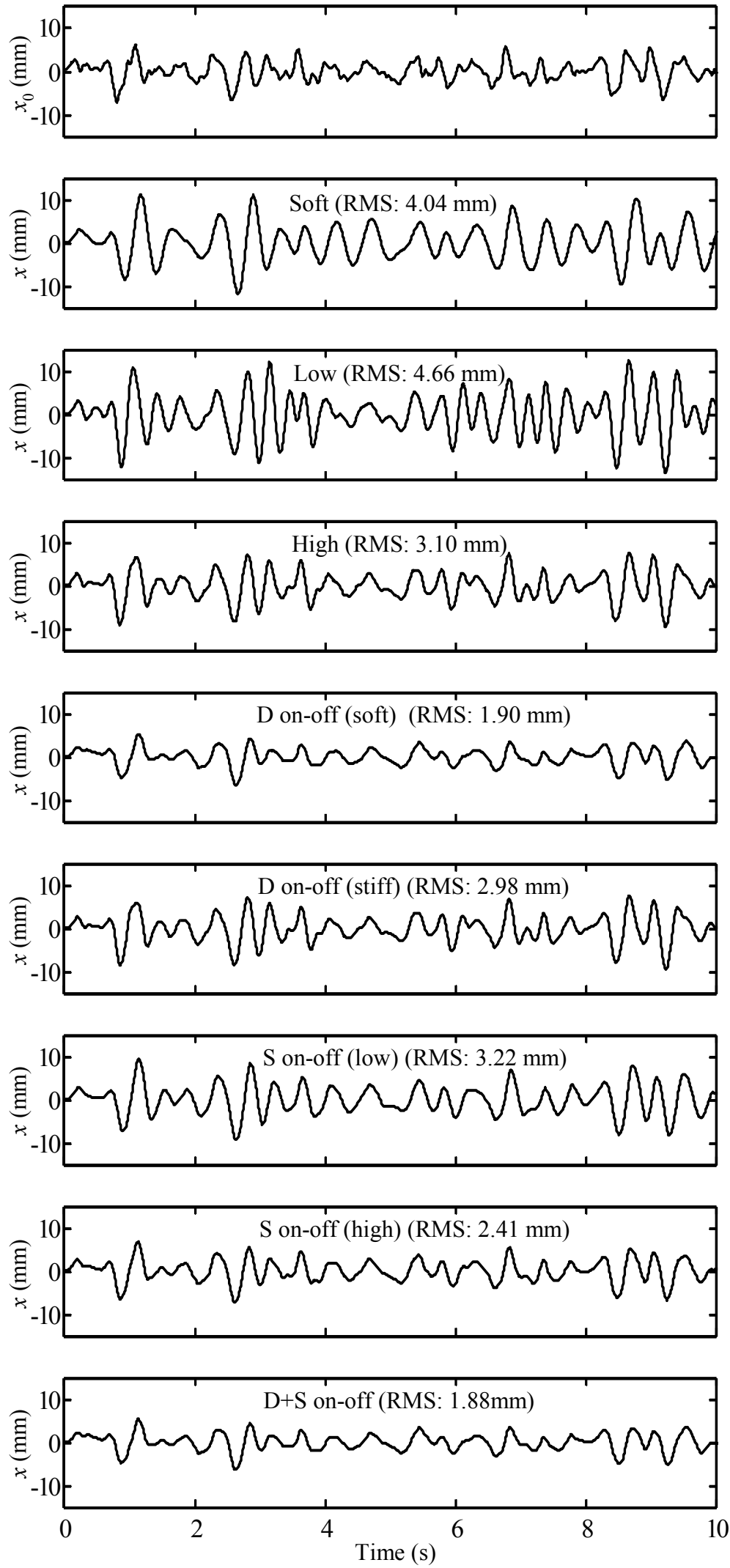

Fig. 10 Random input and time responses.

\section{Conclusions}

A new variable stiffness and damping system configuration using two controllable dampers was proposed. Since the stiffness is controlled by changing the damping coefficient, this system is very simple and easy to apply in 
practical systems. The system is experimentally investigated using the MR damper that the damping can be changed easily.

Based on the experimental and calculation results, the proposed control system has good performances for the vibration isolation, especially, it has the smallest displacement responses. The acceleration is a little larger than those of the soft spring systems, however, the soft spring systems has larger compliance and they are not applicable for the real systems which has not only the base excitation but also the force excitation.

\section{Acknowledgements}

This work was supported by Japan Society for the Promotion of Science (JSPS) (No. 17-05345).

\section{References}

[1] D. Karnopp, M. J. Crosby, R. A. Harwood, Vibration control using semi-active force generators, ASME Journal of Engineering for Industry, Vol. 96, No. 2 (1974), p. 619-626.

[2] E. J. Krasnicki, The experimental performance of an "on-off" active damper, Shock and Vibration Bulletin, No. 51 (1981), p. 125-131.

[3] S. Rakheja, S. Sankar, Vibration and shock isolation performance of a semi-active on-off damper, ASME Journal of Vibration, Acoustics, Stress and Reliability in Design, Vol. 107, No. 4 (1985), p. 398-403.

[4] Y. Liu, H. Matsuhisa, H. Utsuno, J. G. Park, Controllable vibration of the car-body using magnetorheological fluid damper, International Journal of Vehicle System Dynamics Supplement, Vol. 41, No. 4 (2004), p. 627-636.

[5] I. Youn, A. Hac, Semi-active suspension with adaptive capability, Journal of Sound and Vibration, Vol. 180, No. 3 (1995), p. 475-492.

[6] T. Kobori, M. Takahashi, T. Nasu, N. Niwa, K. Ogasawara, Seismic response controlled structure with active variable stiffness system, Earthquake Engineering and Structural Dynamics, Vol. 22, No. 11 (1993), p. 925-941.

[7] Y. Liu, H. Matsuhisa, H. Utsuno, J. G. Park, Vibration isolation by a variable stiffness and damping system, International Journal of Japan Society of Mechanical Engineering (Series C), Vol. 48, No. 2 (2005), p. 305-310.

[8] http://www.rheonetic.com/devices_controllable_friction_damper_begin.htm (last accessed on Aug. 7 $^{\text {th }}, 2003$ ).

[9] Y. Liu, H. Matsuhisa, H. Utsuno, J. G. Park, Vibration control by a variable damping and stiffness with magnetorheological dampers, International Journal of Japan Society of Mechanical Engineering (Series C), Vol. 49, No. 2 (2006), p. 411-417.

[10] Y. Liu, H. Matsuhisa, H. Utsuno, J. G. Park, Variable damping and stiffness control with magnetorheological dampers for a 2-DOF vibration system, International Journal of Japan Society of Mechanical Engineering (Series C), Vol. 49, No. 1 (2006), p. 156-162.

[11] O. Taniguchi, Vibration Engineers' Handbook (in Japanese), The Compiling Committee of Vibration Engineers' Handbook, Yokendo Press, Tokyo, 1976, p. 1127-1128.

[12] ISO 8608: E, Mechanical vibration -- road surface profiles - reporting of measured data, TC 108/SC 2 (Mechanical vibration and shock/measurement and evaluation of mechanical vibration and shocks as applied to machines, vehicles and structures), ISO Standards, 1995.

[13] G. Verros, C. Natsiavas, Design optimization of quarter-car models with passive and semi-active suspensions under random road excitation, Journal of Vibration and Control, Vol. 11, No. 5 (2005), p. 581-606. 